\title{
ARRANJOS POÉTICOS NA LÍNGUA VIVA: UMA EXPERIÊNCIA DIALÓGICA
}

\author{
POETIC ARRANGEMENTS IN THE LIVING LANGUAGE: \\ A DIALOGICAL EXPERIENCE
}

\author{
Marlete Sandra Diedrich | Lattes | marlete@upf.br \\ Universidade de Passo Fundo \\ Edemilson Antônio Brambilla | Lattes | edemilson.brambilla@gmail.com \\ Universidade de Passo Fundo \\ Vinícius Franzen | Lattes \\ Universidade de Passo Fundo
}

Resumo: Este artigo se ocupa da ampliação do horizonte social dos estudantes da Educação Básica nas aulas de Língua Portuguesa a partir de uma experiência de prática de ensino de língua como elemento vivo, cujos arranjos poéticos se constituem significativos na interação verbal. Parte-se do princípio de que os estudos da interação, em especial, aqueles da vertente da Análise Dialógica do Discurso, podem iluminar a discussão da Linguística Aplicada sobre o ensino da Língua Portuguesa na Educação Básica. O objetivo desta reflexão é estabelecer relações entre a prática de ensino de Língua Portuguesa na Educação Básica e a concepção de horizonte social, cuja ampliação resulta de experiências significativas na/com a língua. A metodologia compreende uma pesquisa-ação desenvolvida em uma turma de $1^{\circ}$ Ano de Ensino Médio de uma escola pública de Passo Fundo/RS a partir do trabalho com a linguagem poética. $O$ trabalho realizado permitiu concluir que a prática de ensino de Língua Portuguesa envolve não apenas a discussão da língua como objeto de estudo, mas, principalmente, da língua como fenômeno social, marcada pelo conteúdo ideológico, pelo conteúdo relativo à vida, sendo os arranjos poéticos um modo de se vivenciar a realidade social e cultural, capaz de estabelecer sentido pelos efeitos que causa nas pessoas e na vida em sociedade.

Palavras-chave: Horizonte social. Sentido. Pesquisa-ação. 
Abstract: This article deals with the social horizon expansion of basic education students in Portuguese classes from a practical experience having the language as a living element, in which the poetic arrangements are significant in the verbal interaction. We start from the principle that the interaction studies, specially the ones from the Dialogical Discourse Analysis, can enlighten the Applied Linguistic discussion in Portuguese teaching in Basic Education. The goal of this reflection is to establish the relations between practice and the social horizon concept, considering the expansion results from the meaningful experiences in/with the language. The methodology comprehends a research-action working with poetic language, which was developed in a first year high school class from a public school in Passo Fundo city, state of Rio Grande do Sul,. The work allowed us to conclude that the practice in Portuguese teaching does not only involve the discussion of language as subject of study, but mainly the language as a social phenomenon, marked by the ideological matter, by the subject related to life, in which the poetic arrangements are a way to live the social and cultural reality capable to establish meaning through their effects on people and on life in society.

Keywords: Social horizon. Sense. Action-research.

\section{Introdução}

Este artigo é derivado dos estudos realizados sobre interação conversacional, os quais ocorrem em nosso grupo de pesquisa cadastrado no diretório do Conselho Nacional de Pesquisa - CNPq, Linguagens, letramento, formação de professores e inovação metodológica. Este grupo é formado por estudantes de graduação de Letras, do curso de Pós-Graduação em Letras da Universidade de Passo Fundo, como também por professores da Instituição e da Educação Básica. Nos trabalhos mais recentes, o interesse de parte deste grupo tem se voltado para as relações interacionais entre professores e estudantes da Educação Básica, em especial, para as interações vivenciadas nas aulas de Língua Portuguesa. Acerca desse tema, destacam-se, no mesmo grupo de pesquisa, trabalhos em nível de Mestrado, tais como $O$ movimento responsivo e o arranjo tópico em sala de aula, de Karina Rigo; A proximidade na interação professor-aluno(s): um olhar para as estratégias discursivas, de Fernanda Poloshi Zat; A dinâmica interacional em um colégio da Brigada Militar: os rituais de interação, as vozes sociais e as fronteiras discursivas, de João Ricardo Fagundes dos Santos.

Acreditamos que o trabalho que aqui apresentamos se insere na pauta dos temas da Linguística Aplicada, uma vez que ele se volta para a prática de ensino de Língua 
Portuguesa em uma turma da Educação Básica. Tal trabalho coloca em evidência uma importante tríade: a língua viva, os sujeitos envolvidos e a troca interacional promovida em sala de aula. É sustentado por esta tríade que o tema deste artigo se constitui: a ampliação do horizonte social dos estudantes da Educação Básica nas aulas de Língua Portuguesa, a partir de uma experiência de prática de ensino de língua como elemento vivo, cujos arranjos poéticos se constituem significativos na interação verbal.

O objetivo é estabelecer relações entre a prática de ensino de Língua Portuguesa na Educação Básica e a concepção de horizonte social, cuja ampliação resulta de experiências significativas na/com a língua. Perseguindo este objetivo, percebemos que os arranjos poéticos da língua, quando estudados a partir de uma concepção de língua como fenômeno social, podem se revelar extremamente significativos para os estudantes. Por essa razão, uma ação de interação em sala de aula de Língua Portuguesa numa turma de $1^{\circ}$ ano do Ensino Médio de uma escola pública de Passo Fundo/RS ilustra a concepção aqui defendida. A referida ação representa o que entendemos por uma prática aplicada de ensino de Língua Portuguesa no universo de uma pesquisa-ação. Pesquisa-ação é entendida em nosso grupo como uma pesquisa que projeta uma intervenção na realidade, no nosso caso, na realidade da escola.

A partir dessa breve contextualização, já podemos apresentar a forma como organizamos o artigo: inicialmente, situamos teoricamente a proposta de ensino de língua aqui apresentada e o universo de pesquisa do qual ela faz parte, o qual se constitui na vertente da Análise Dialógica do Discurso; na sequência, detalhamos a proposta em seu viés metodológico, para, por fim, discutir os resultados alcançados e apresentar as considerações finais.

\section{A Análise Dialógica do Discurso: conceitos basilares para o ensino de língua}

Enquanto, no início do século XX, a Linguística tradicional delegava importante espaço para a compreensão da língua como representação objetiva e evidente da realidade, para Mikhail Bakhtin e seu Círculo de pensadores, o que importava era compreender a língua em sua dimensão social, histórica e dialógica. Com uma crítica direta à grande parte dos pressupostos advindos dos estudos linguísticos da época, bem como às teorias universalizantes, o pensamento bakhtiniano caracteriza-se por apostar em um indivíduo único, evêntico, fragmentado, e em constante transformação e diálogo com o meio social em que está inserido.

A Análise Dialógica do Discurso (ADD) postula que enunciados e locutores entram constantemente em relações dialógicas entre si. Para essa perspectiva, todo enuncia- 
do é uma réplica a outros enunciados, sejam eles ditos ou não, e o fato de serem passíveis de resposta já lhes confere esse caráter de interdependência. Ao analisar de modo mais detalhado tal conceito, Fiorin (2016, p. 21-22) afirma que:

Segundo Bakhtin, a língua, em sua totalidade concreta, viva, em seu uso real, tem a propriedade de ser dialógica. Essas relações dialógicas não se circunscrevem ao quadro estreito do diálogo face a face, que é apenas uma forma composicional, em que elas ocorrem. Ao contrário, todos os enunciados no processo de comunicação, independentemente de sua dimensão, são dialógicos. Neles, existe uma ideologização interna da palavra, que é perpassada sempre pela palavra do outro, é sempre e inevitavelmente a palavra do outro. Isso quer dizer que o enunciador, para constituir um discurso, leva em conta o discurso de outrem, que está presente no seu. Por isso, todo discurso é inevitavelmente ocupado, atravessado, pelo discurso alheio.

Esse olhar é fundamental para entendermos a concepção de linguagem assumida pela ADD, já que, segundo Sobral e Giacomelli (2016), a ADD entende que a linguagem tem dois componentes: o componente formal, que é a língua, que traz significações, de caráter mais geral; e o componente discursivo, ligado à enunciação e ao sentido, sendo este último produzido na particularidade do discurso e não dado previamente. Para a $\mathrm{ADD}$, não se pode entender o discurso sem a língua, mas também não se pode entender o discurso, que é o uso da língua, sem levar em conta que a produção do enunciado (do discurso) vai além da língua e cria linguagem.

Dessa perspectiva deriva outra distinção bastante clara feita pelos pensadores do Círculo, a saber: tema e significação. O primeiro caso, o tema, segundo Bakhtin/ Volochínov (2010), é o estágio superior real da capacidade linguística de significar, pois, apenas o tema significa de maneira determinada. A significação, por sua vez, é o estágio inferior da capacidade de significar, já que ela não quer dizer nada em si, é apenas um potencial, uma possibilidade de significar no interior de um tema concreto.

Ainda segundo esses pensadores, a investigação da significação de um elemento linguístico pode tanto voltar-se ao estágio superior, ou tema, e analisar a significação contextual de uma determinada palavra nas condições de uma enunciação concreta; ou ela pode, do contrário, voltar-se ao estágio inferior, o da significação, sendo assim a investigação da significação da palavra no sistema da língua.

Uma distinção clara entre o tema e a significação é alcançada por meio do ato de compreender. Isso porque quando um enunciado é verdadeiramente compreendido, tem-se uma compreensão ativa, a qual leva em conta a possibilidade de uma resposta 
a este enunciado, ou, uma possibilidade de diálogo, opondo, à palavra do locutor, uma contrapalavra. Assim, conforme Bakhtin/Volochínov (2010, p. 137), "compreender a enunciação de outrem significa orientar-se em relação a ela, encontrar o seu lugar adequado no contexto correspondente". A cada palavra do enunciado que compreendemos, fazemos com que ela dialogue diretamente com as nossas, dando origem a uma réplica ao outro enunciado, que é dotada de valoração, e marcadamente ideológica. Nas palavras de Bakhtin/Volochínov (2010, p. 137):

Toda palavra usada na fala real possui não apenas tema e significação no sentido objetivo, de conteúdo, desses termos, mas também um acento de valor ou apreciativo, isto é, quando um conteúdo objetivo é expresso (dito ou escrito) pela fala viva, ele é sempre acompanhado por um acento apreciativo determinado. Sem acento apreciativo, não há palavra.

É possível afirmar, então, que os signos usados para produzir um enunciado carregam consigo determinada posição ideológica do enunciador, e analisar tal discurso aponta, também, para a necessidade de considerar o contexto em que determinado indivíduo está inserido no momento em que enuncia. Para Sobral e Giacomelli (2016, p. 1083), todo signo é usado no discurso a partir de dada posição social e histórica de um locutor diante de seu interlocutor. Não recebemos palavras neutras na língua, mas signos que vêm de pessoas reais e revelam uma valoração, ou avaliação, do que é dito.

Desse modo, conforme os dois autores supracitados, nenhum dizer é inocente, ingênuo, gratuito, pois sempre está ligado aos interesses de quem diz (mesmo que o locutor nem saiba que interesses são esses). É preciso considerar, então, que todo enunciado é interessado, ou seja, é algo com que o locutor deseja realizar seu projeto de dizer, aquilo que ele quer que o outro aceite como bom, verdadeiro, correto, etc., a fim de valer seus interesses. Ademais, isso se deve também ao fato de que, ao enunciar, o locutor o faz refletindo toda a carga ideológica a que está exposto, construída em diálogo com o meio no qual está inserido. A esse respeito, Bakhtin/Volochínov (2010, p. 116-117) afirma que:

$\mathrm{Na}$ maior parte dos casos, é preciso supor um certo horizonte social definido e estabelecido que determina a criação ideológica do grupo social e da época a que pertencemos, um horizonte contemporâneo da nossa literatura, da nossa ciência, da nossa moral, do nosso direito. $\mathrm{O}$ mundo interior e a reflexão de cada indivíduo têm um auditório social próprio bem estabelecido, em cuja atmosfera se constroem suas deduções interiores, suas motivações, apreciações, etc. 
Portanto, todo enunciado carrega uma forte carga ideológica, advinda de todos os aspectos formativos do enunciador, sejam eles ligados ao seu horizonte social, ou ao seu auditório social, pois, é no momento em que seu agir se materializa em discurso, e se dirige, necessariamente, a um outro, que essas características ideológicas passam a se marcar em seu ato enunciativo, já que, compreendemos e enunciamos o mundo mediados pelo prisma do meio social concreto que nos engloba, ou, nas palavras de Bakhtin/Volochínov (2010, p. 116), "qualquer que seja o aspecto da expressão-enunciação considerado, ele será determinado pelas condições reais da enunciação em questão, isto é, antes de tudo pela situação social mais imediata”.

Para Faraco (2009), a enunciação de um signo é sempre também a enunciação de índices sociais de valor, isto é, a enunciação de um signo tem efeitos de sentido que decorrem da possibilidade de sua ancoragem em diferentes quadros semântico-axiológicos, em diferentes horizontes sociais de valores. É por meio dessas interações que as relações dialógicas se constituem, sendo inerente ao enunciado uma tomada de posição axiológica, uma resposta ao já dito, tendo em vista que a resposta é esperada quando o enunciado é dito. Assim, por ser heterogeneamente constituído, ele está permanentemente atravessado por uma dialogização interna.

É através do contato com o meio social, constituindo-se através de enunciados concretos, e expondo-se a novas relações dialógicas, que o sujeito alcança a ampliação de seu horizonte e, por conseguinte, de seu auditório social. Isso ocorre por meio de um processo no qual o signo é compreendido e interpretado, para que possa, posteriormente, ser interiorizado de maneira significativa para o sujeito. A interiorização acontece, segundo Corazza (2019, p. 68), por meio de um processo de comunicação social, o qual é determinado como horizonte social, já que, nas palavras de Bakhtin/Volochínov (2010, p. 46): "não pode entrar no domínio da ideologia, tomar forma e aí deitar raízes senão aquilo que adquiriu um valor social”.

É com essa concepção de língua e horizonte social, portanto, que apresentamos, na sequência, uma das ações ilustrativas da pesquisa-ação por nós desenvolvida, reveladora do deslocamento dialógico realizado pelo sujeito na linguagem.

\section{A Análise Dialógica do Discurso e a Educação Básica: uma ação aplicada}

É com base nos preceitos teóricos anteriormente expostos que analisamos, nesta seção, a experiência vivenciada junto a uma turma de alunos do $1^{\circ}$ ano do Ensino Médio de uma escola pública da cidade de Passo Fundo/RS, interpretando-a sob a ótica da 
Análise Dialógica do Discurso. Inicialmente, apresentamos, para fins de contextualização e clareza, um breve relato da proposta e algumas das nuances dialógicas que caracterizaram a interação entre os sujeitos diretamente envolvidos, uma vez que entendemos ser importante dar a conhecer, ao menos em linhas gerais, o contexto interacional vivenciado. Somente depois dessa contextualização é que nos voltamos para a especificidade de nosso tema.

As experiências vivenciadas pelo grupo de pesquisadores na turma dividiram-se em três encontros - realizados entre os meses de setembro e outubro de 2019. Tal aproximação se deu através de atividades que buscaram dialogar com a realidade dos alunos, com o propósito de dar maior significância ao fazer educacional e, ao mesmo tempo, evidenciar as relações dialógicas presentes no ambiente escolar, tendo o trabalho com a Língua Portuguesa como referência. Para tanto, foram escolhidas algumas temáticas norteadoras para os debates, a saber: medo e coragem.

O primeiro encontro, pautado na aproximação dos pesquisadores com os alunos em seu ambiente escolar, teve como norteador das ações o poema intitulado Medo, de Bráulio Bessa. Estabeleceu-se, a partir dele, um diálogo inicial com os estudantes, uma troca de vivências, por assim dizer. Isso resultou em uma discussão a respeito do tema, a partir da qual os alunos passaram a relatar suas próprias experiências de medo, e como fazem para enfrentá-las. Um dos principais relatos feitos por estes estudantes abordava o medo que sentiram no momento de sua inserção em um ambiente escolar novo e totalmente desconhecido, no qual, acreditamos, a carga ideológica de um sujeito apresenta características bastante distintas em relação aos demais, implicando, em um primeiro momento, o medo da não aceitação pelos outros, e uma noção de não-pertencimento, resultando, por sua vez, em uma dificuldade de interação e inserção no novo grupo social.

Esse relato decorre, provavelmente, da certeza, por parte desses alunos, de que o referido medo também era comum aos demais, fazendo com que a estrutura da enunciação fosse marcadamente influenciada pela carga ideológica inerente ao grupo, pois, como nenhum outro aluno relatou seus medos ou experiências particulares, o apelo ao medo comum entre eles lhes pareceu mais confortável de ser relatado. Nesse sentido, Bakhtin/ Volochínov (2010, p. 117) afirma que "a situação social mais imediata e o meio social mais amplo determinam completamente e, por assim dizer, a partir do seu próprio interior, a estrutura da enunciação”.

Em relação às primeiras manifestações dos estudantes na interação objeto de análise, as quais foram poucas e tímidas, é importante lembrar que há, no sujeito, certa autono- 
mia em relação à exposição e aos atravessamentos ideológicos e culturais que a sociedade lhe impõe. Nas palavras de Fiorin (2016, p. 64):

\begin{abstract}
O mundo interior éformado a partir da heterogeneidade dialógica das vozes sociais. Os enunciados, construídos pelo sujeito, são constitutivamente ideológicos, pois são uma resposta ativa às vozes interiorizadas. Por isso, eles nunca são expressão de uma consciência individual, descolada da realidade social, uma vez que ela é formada pela incorporação das vozes sociais em circulação na sociedade. Mas, ao mesmo tempo, o sujeito não é completamente assujeitado, pois ele participa do diálogo de vozes de uma forma particular, porque a história da constituição de sua consciência é singular. Ele é um evento único, porque responde às condições objetivas do diálogo social de uma maneira específica, interage concretamente com as vozes sociais de um modo único.
\end{abstract}

Com base nos estudos de Bakhtin/Volochínov (2010) e Freire (1996), é preciso levar em conta que o estudante em ambiente escolar pode optar pelo silenciamento como forma de manifestar sua escolha pelo não-pertencimento àquela situação ou mesmo àquele grupo. No entanto, esta escolha não pode ser entendida como neutra, devido à carga ideológica inerente a todos os aspectos que a constituem enquanto tal, fazendo de sua posição também um ato político e ideológico, uma escolha diretamente definidora de si enquanto sujeito: a de não pertencer.

Certamente nem sempre a escolha pelo não-pertencimento está vinculada a uma atitude autônoma, ligada à liberdade e às concepções inerentes ao próprio indivíduo. Por vezes, isso se deve a fatores que alteram, ao menos em partes, o plano de organização social e os princípios que regem determinados grupos, o que faz com que um subgrupo tenda a se diferenciar de outro por questões mais imediatas, como o fato de haver, em meio a esta turma de alunos, duas alunas com deficiência auditiva, o que parece influenciar diretamente o fazer educacional naquele ambiente escolar. Mesmo com a presença de uma intérprete, que, do ponto de vista didático, parece facilitar a prática docente diante da turma, por outro lado - e também do ponto de vista interacional -, aponta para questões concretas que definem o agir e a posição social que essas alunas inclusas assumem.

Ainda que este não seja o principal foco de análise deste trabalho, suscitando um estudo futuro a esse respeito, é preciso considerar que, do ponto de vista bakhtiniano, a mediação feita pela intérprete confere uma influência significativa na relação entre locutor e interlocutor, fazendo com que os enunciados produzidos pela professora assumam nova carga ideológica. A questão se torna mais complexa ainda quando o objeto de estudo é um texto poético, no qual a forma específica de se organizar a mensagem numa 
dada língua é determinante para a reflexão proposta. Mas esta é, no momento, apenas uma questão contextual e não o tema deste artigo. Desse aspecto nos ocuparemos em outras reflexões.

O encontro seguinte, por sua vez, teve como norteador das atividades o conto intitulado Olhos d'água, de Conceição Evaristo. A partir do conto, alguns questionamentos embasaram o debate em sala de aula, a saber: "Que tipo de relato está sendo feito no conto?", "Vocês se identificaram com algum ponto do texto? E, por quê?".

Como resposta, alguns alunos afirmaram não se identificar com a temática tratada no texto de Conceição Evaristo - situações cotidianas da comunidade negra/afro-brasileira urbana. Relacionamos a posição dos estudantes ao pensamento bakhtiniano, mais especificamente, ao fato desses alunos possuírem ou pensar que possuem um horizonte social e um auditório social distinto da realidade apresentada no conto. Os que se identificaram, por outro lado, acabaram por se colocar no lugar do outro, identificando pequenas semelhanças entre si e a vivência transcrita no texto.

Em seguida, os pesquisadores apresentaram aos alunos o conceito de "escrevivência”, termo cunhado por Conceição Evaristo para designar o processo de escrita das vivências de cada indivíduo, ou seja, parte-se da experiência do autor para viabilizar narrativas que dizem respeito a uma experiência coletiva. É esta a concepção basilar que fundamenta a proposta feita aos alunos da escola, para que, em atividades futuras, possam produzir suas próprias "escrevivências", as quais, à semelhança do que se viu nos textos de Conceição Evaristo, são construídas a partir de jogos de linguagem, de relações de sentido marcadamente metafóricas e metonímicas, as quais só podem ser entendidas a partir de uma leitura que olhe para além das palavras, que olhe para as relações estabelecidas no meio social do sujeito que se revela ao dizer, as quais encontram na palavra e nos arranjos poéticos um meio de expressão de vivências muito particulares, cujo sentido se constrói e se particulariza por meio da escrita, logo, podem ser entendidas como "escrevivências".

Essa proposta pode ser compreendida também através de seu caráter marcadamente dialógico, já que, ao passo em que os alunos fazem suas próprias “escrevivências", consideram também a presença de um interlocutor nesta escrita, delegando grande importância à relação eu/outro, concepção fundamental para a teoria bakhtiniana. Bakhtin/ Volochínov (2010) compreende a linguagem, e a palavra, de um modo especial, como sendo um importante meio enunciativo que permite com que o sujeito se defina em relação ao outro e ao coletivo. Esse ato de enunciar passa a ser o produto da interação entre dois indivíduos socialmente organizados, determinados por sua condição real e por 
sua situação social mais imediata. Assim, a palavra é determinada tanto pelo fato de que procede de alguém - do aluno, no caso das "escrevivências" -, como pelo fato de que se dirige para alguém, constituindo-se como o produto da interação entre o locutor e seu interlocutor. Dessa maneira, a concepção dialógica se constitui em sua plenitude, e as "escrevivências" destes alunos, longe de serem dotadas de neutralidade, expressam seu posicionamento ideológico, e o definem para si, e para a sociedade de um modo geral. E fazem isso por meio, principalmente, de arranjos poéticos, os quais, nesse contexto, são compreendidos como elementos singulares na experiência com a linguagem e justamente por isso podem ser vistos como fundamentais na ampliação do horizonte social dos sujeitos que deles fazem uso, conforme estamos propondo neste artigo.

Visando aprimorar as relações interacionais propostas pelo grupo, em sua última interação, os alunos da escola deslocaram-se até o Laboratório de Estudos Linguísticos e Literários Mundo da Leitura, no campus da Universidade de Passo Fundo, com o intuito de conhecer o ambiente acadêmico. Foram recepcionados com a música AmarElo, do rapper Emicida, e com questões norteadoras para o debate, sendo que algumas delas foram: "Você já sentiu medo de sair de casa? ", "Você já teve que atravessar a rua à noite porque alguém vinha na direção oposta? ", "Você já teve medo de sentar ao lado de alguém no ônibus?".

Evidenciamos, nesta etapa, uma identificação maior por parte dos alunos com relação à temática do medo, pois, apesar de reações contidas e respostas breves, ficaram evidentes a familiaridade e a proximidade dos estudantes com o que fora retratado nas questões norteadoras. Assim, é possível afirmar que a temática que vinha dando base às aproximações com a turma dialogou de modo mais concreto com o horizonte social e com a realidade vivenciada cotidianamente por esses estudantes, os quais relataram algumas situações concretas por eles já vivenciadas, falaram de suas experiências pessoais e de como essas questões se presentificam em suas vidas. Mas o grande momento da interação ainda estava por vir.

Dando continuidade às atividades propostas, os bolsistas do Projeto realizaram uma leitura dramatizada do conto Maria - que segue a mesma linha temática do conto utilizado no encontro anterior -, de Conceição Evaristo, com o intuito de promover uma experiência diferenciada aos estudantes, com o uso da expressão vocal como grande recurso de estabelecimento de sentidos singulares no texto lido. Depois, os estudantes realizaram a leitura silenciosa e individual do mesmo texto, para, em seguida, ser lançado o questionamento: "Qual foi sua experiência com a leitura dramatizada? E com a indivi- 
dual? ”. Assim abriu-se a discussão visando à análise da materialidade do texto, por meio da qual se percebeu a riqueza e profundidade de cada detalhe existente na construção do conto, fazendo jus à "escrevivência” de Conceição Evaristo.

Ao relatarem suas impressões referentes à leitura dramatizada, os estudantes consideraram-na mais proveitosa em relação à individual, pois compreenderam com maior facilidade o panorama geral do enredo do conto de Conceição Evaristo. A leitura individualizada, por sua vez, foi importante para auxiliar na compreensão de aspectos mais particulares da construção da narrativa, a exemplo de enunciados como: "faca-laser que corta até a vida" e "será que os meninos gostavam de melão? ", as quais, analisadas no contexto específico do conto, revelam metáforas e metonímias possíveis em função da forte carga ideológica que as relações de sentido construídas no discurso mobilizam, transcendendo a compreensão do texto enquanto um sistema de signos totalmente transparente ao sujeito. Não nos deteremos aqui em apresentar todos os enunciados cujos arranjos poéticos foram analisados, mas precisamos esclarecer que a análise realizada contou com a participação efetiva dos estudantes, os quais assumiram o seu espaço de dizer, posicionando-se acerca das escolhas do enunciador do texto a partir da particularidade do contexto social apresentado, o de uma empregada doméstica, o qual contrasta com o contexto social da personagem patroa, por exemplo, ou com o contexto social do pai da criança, outra personagem do conto. E é essa compreensão que permite entender o elemento "melão" não apenas como uma mera fruta citada no texto, mas como um objeto-valor que denuncia a desigualdade social, uma vez que a ele nem todos têm acesso, constituindo-se, assim, o arranjo poético metonímico por meio do qual o signo "melão" assume novos temas na particularidade da enunciação. Essa mesma relação é constituída no texto e percebida pelos estudantes com o uso do signo "faca laser", o qual representa muito mais do que um simples objeto cortante de uso na cozinha, pois, quando associado ao enunciado "corta até a vida", assume um outro modo de dizer, uma outra maneira de o sujeito mobilizar a língua: é a especificidade do poético, capaz de dizer mais do que está sendo afirmado, já que estabelece relações de sentido inovadoras e renovadoras da significação linguística, assumidas na compreensão da subjetividade da personagem exposta no texto, em especial, em relação às suas vivências.

Situação semelhante foi experienciada ao final do encontro, com a apresentação de dois vídeos: primeiramente, o videoclipe completo da música AmarElo, e, logo após, o vídeo A história por trás do clipe, no qual as diversas histórias dos personagens de AmarElo, moradores do Morro do Alemão, no Rio de Janeiro, são narradas. Os vídeos foram exibi- 
dos sem maiores discussões, uma vez que o objetivo era apenas apresentar as narrativas presentes na música e seu contexto social, para que os estudantes pudessem sair daquele encontro levando possibilidades de reflexão em torno do modo como as adversidades, medos e a necessidade de continuar vivendo, lutando, a coragem, portanto, foram retratadas pelos arranjos poéticos de AmarElo, os quais são ricos e reveladores de construções muito singulares do ponto de vista do sentido, como atesta o sample de Sujeito de Sorte, de Belchior, refrão da música de Emicida: "Tenho sangrado demais, tenho chorado pra cachorro/Ano passado eu morri, mas esse ano eu não morro". O sample se presentifica no mundo da música como um recurso de construção no qual um fragmento (uma amostra) de outra obra já existente é usado para compor nova obra. No caso de AmarElo, o uso do sample provoca a discussão acerca da renovação de sentidos num contexto social e histórico, uma vez que Sujeito de Sorte, de Belchior, de 1976, certamente retratava questões sociais distintas das de hoje, as quais são retomadas em parte, mas ressignificadas numa nova enunciação em AmarElo. Esse processo de construção de sentido merece reflexão quando se analisa a língua viva e seus arranjos poéticos, por isso, acreditamos que tal processo tenha sido levado em conta pelos estudantes em suas análises.

A pesquisa-ação ainda está em desenvolvimento e por essa razão não pretendemos neste artigo apresentar seus resultados finais. Acreditamos que com a análise dessa ação específica com os textos poéticos conseguimos ilustrar a proposta que ora propomos, o que nos permite refletir acerca dos resultados alcançados com esta ação em específico.

\section{Resultados alcançados}

Com a prática desenvolvida, alguns resultados podem ser dados como alcançados, destacando-se, entre eles, o fato de que a interação entre os sujeitos envolvidos na ação foi além do que comumente se vê nas interações em sala de aula entre professor e aluno, as quais, na maioria das vezes, se dão a partir de discursos pautados na relação de poder, numa tentativa de serem de natureza monologizante, uma vez que o dizer do professor em geral é o único validado. $\mathrm{Na}$ ação relatada, todos os sujeitos envolvidos construíram projetos de dizer, constituídos por relações sociais e interacionais diferentes entre si, extremamente dialógicas, como se espera que devam ser as interações na área da educação. Com essa concepção, é possível romper, ao menos parcialmente, a realidade de um fazer educacional conservador e pautado somente na figura central do professor - agora somente mediador desse conhecimento -, o que, conforme Freire (1996) e (1987), delega ao aluno maior autonomia do fazer educacional, com a possibilidade de dialogar com seu horizonte social. 
Tais resultados são imprescindíveis para que possamos chegar à satisfação do objetivo proposto nesta reflexão. Lembremo-nos dele: estabelecer relações entre a prática de ensino de Língua Portuguesa na Educação Básica e a concepção de horizonte social, cuja ampliação resulta de experiências significativas na/com a língua.

Com certeza, é possível afirmar que uma experiência significativa na/com a língua só se concretiza quando há um envolvimento do sujeito com a realidade a ele apresentada. Assim, todos os textos caracterizados por arranjos poéticos apresentados aos estudantes do $1^{\circ}$ Ano do Ensino Médio foram analisados a partir da concepção particular e da vivência particular dos estudantes leitores, os quais, com o auxílio dos pesquisadores-professores, puderam efetuar deslocamentos de sentido a partir dos arranjos poéticos percebidos; tais deslocamentos se tornaram viáveis em função da concepção de "língua viva” assumida pela ação em questão: a língua mobilizada nas enunciações apresentadas nos textos revela vivências particulares dos locutores que encontram espaço de voz para suas experiências carregadas de significado na vida em sociedade. Outro deslocamento possível nesta ação é o fato de que o dizer do outro não é somente dele, uma vez que eu posso também me identificar de alguma forma com esse dizer, aceitando-o ou confrontando-o, na simples realização do que apregoa Bakhtin/ Volochínov (2010, p. 141):

O criador de gado pré-histórico não tinha preocupações, não havia muita coisa que realmente o tocasse. O homem da era capitalista está diretamente relacionado com todas as coisas, seus interesses atingem os cantos mais remotos da terra e mesma as mais distantes estrelas. Esse alargamento do horizonte apreciativo efetua-se de maneira dialética. Os novos aspectos da existência, que foram integrados no círculo do interesse social, que se tornaram objetos da fala e da emoção humana, não coexistem pacificamente com os elementos que se integram à existência antes deles; pelo contrário, entram em luta com eles, submetem-nos a uma reavaliação, fazem-nos mudar de lugar no interior da unidade do horizonte apreciativo. Essa evolução dialética reflete-se na evolução semântica. Uma nova significação se descobre na antiga e através da antiga, mas a fim de entrar em contradição com ela e de reconstruí-la.

O fato de a ação nesta turma ter propiciado aos estudantes a oportunidade de acessar a experiência do outro, via arranjos poéticos, é uma possibilidade de ampliação do horizonte social desses estudantes, uma vez que os arranjos poéticos passam a ser ressignificados em sua própria experiência, assim como "os aspectos da existência” neles envolvidos. 


\section{Considerações finais}

Certamente para alguns a reflexão aqui apresentada pode parecer ousadia ou mesmo incompreensão do que de fato se entende por Linguística Aplicada. Assumimos o caráter ousado da proposta, mas refutamos o da incompreensão. Fazemos isso pautados na ideia de Teixeira (2012), segundo a qual a Linguística é uma ciência poderosa, especialmente porque está relacionada ao conhecimento sobre o homem. Com esse olhar, assumimos a convicção de que a Linguística, ciência poderosa, com tantos desdobramentos, não pode cair no reducionismo, pelo contrário, precisa aproveitar os diversos estudos que se realizam no seu escopo para melhor compreender o homem que fala, que escreve, que interage. Dessa forma, acreditamos que os estudos acerca da interação, tal qual têm se realizado na vertente da $\mathrm{ADD}$, podem ser acolhidos no universo da Linguística Aplicada, principalmente, quando se trata de experiências de ensino em ambientes institucionalizados como a escola.

As pesquisas realizadas até aqui neste universo têm mostrado o quão importante é garantir aos estudantes da Educação Básica, em especial, nas escolas públicas, interações que lhes possibilitem se sentir parte do processo de ensino e aprendizagem, interações nas quais a língua viva compareça como elemento que "conecta os participantes da situação" (VOLÓCHINOV, 2019, p. 119), uma vez que se conecta com a vida. Temos plena certeza de que os arranjos poéticos analisados nas enunciações das quais nos ocupamos em nossa ação assumem esse caráter social.

\section{Referências}

BAKHTIN, Mikhail (Volochínov). Marxismo e filosofia da linguagem: problemas fundamentais do método sociológico da linguagem. 14.ed. São Paulo: Hucitec, 2010. $203 p$.

BELCHIOR, Antonio Carlos. Sujeito de sorte. Disponível em: https://www.youtube. com/watch?v=5MV_Fa3MQuA. Acesso em: 05 de fevereiro de 2020.

BESSA, Bráulio. Medo. In: BESSA, Bráulio. Poesia que transforma. Rio de Janeiro: Sextante, 2018. p. 32.

CORAZZA, Maritana. As redes sociais digitais e a ampliação do horizonte valorativo. 2019 . 94 f. Dissertação (Mestrado em Letras) - Instituto de Filosofia e Ciências Humanas, Universidade de Passo Fundo, Passo Fundo, 2019.

EMICIDA. AmarElo. Disponível em: https://www.youtube.com/ watch?v=PTDgP3BDPIU. Acesso em: 03 de fevereiro de2020.

EMICIDA. As histórias por trás do clipe. Disponível em: https://www.youtube.com/ watch? $=$ w6A0ySjhaHA\&t=213s. Acesso em: 03 de fevereiro de 2020. 
EVARISTO, Conceição. Maria. In: EVARISTO, Conceição. Olhos d'água. Rio de Janeiro: Pallas, 2014. p. 39-42.

EVARISTO, Conceição. Olhos d'água. In: EVARISTO, Conceição. Olhos d'água. Rio de Janeiro: Pallas, 2014. p. 15-20.

FARACO, Carlos. A. Linguagem \& diálogo: as ideias linguísticas do Círculo de Bakhtin. 1.ed. São paulo: Parábola Editorial, 2009. $168 \mathrm{f}$.

FIORIN, J. L. O dialogismo. In: Introdução ao pensamento de Bakhtin. São Paulo: Contexto, 2016. p. 21-65.

FREIRE, Paulo. Pedagogia da autonomia: saberes necessários à prática educativa. 25. ed. São Paulo: Paz e Terra, 1996.

FREIRE, Paulo. Pedagogia do oprimido. 17. ed. Rio de Janeiro: Paz e Terra, 1987.

SOBRAL, Adail; GIACOMELLI, Karina. Observações didáticas sobre a Análise Dialógica do Discurso - ADD. Revista Domínios de Lingu@gem, Uberlândia, vol. 10, n. 3, p. 1076 - 1094, jul./set. 2016.

TEIXEIRA, Marlene. O estudo dos pronomes em Benveniste e o projeto de uma ciência geral do homem. Revista Desenredo, Passo Fundo, vol. 8, n. 1, 2012. Disponível em: http:/ / seer.upf.br/index.php/rd/article/view/2639. Acesso em: 03 de fevereiro de 2020.

VOLÓCHINOV, Valentin (Círculo de Bakhtin). A palavra na vida e a palavra na poesia. Organização, tradução, ensaio introdutório e notas de Sheila Grillo e Ekaterina Vólkova Américo. São Paulo: Editora 34, 2019. 